\title{
The effects of structural change: An investigation into the South African cricket development pathway
}

\author{
Cedric English \\ School of Applied Sciences, Edinburgh Napier University, UK, \\ Telephone 0131455 5704, email c.english@napier.ac.uk \\ Christine Nash \\ Institute for Sport, PE, and Health Sciences, The University of Edinburgh, UK \\ Telephone 0131651 6581, email cnash@ed.ac.uk \\ Russell Martindale \\ School of Applied Sciences, Edinburgh Napier University, UK \\ Telephone 0131455 2625, email r.martindale@napier.ac.uk
}

Correspondence concerning this article should be addressed to Cedric English, School of Applied Sciences, Edinburgh Napier University, Sighthill Campus, Edinburgh, EH11 4BN. Telephone 0131455 5704, E-mail: c.english@napier.ac.uk 


\title{
The effects of structural change: An investigation into the South African cricket
}

\section{development pathway}

\begin{abstract}
Sports organisations face immense challenge, both structurally and organisationally, in coordinating talent development processes. This complex interaction may be exacerbated by structural change and sports policy decision-making, not only changing the way pathway elements interact and individuals progress, but also the quality of the learning and development domain. The aim of this research was to investigate the development pathway of South African cricketers and the impact of change to the provincial structure in 2004. Twelve semi-structured interviews with highly experienced players, coaches and administrators raised a number of themes. Specifically, the changes reduced elite playing opportunities and narrowed pathway options. Club cricket standards dropped, reducing its viability as a pool for talent identification and effective development. This placed stress on age-related academies as a fundamental development environment and the need to select talent 'into the system' earlier, which has implications for late developers and the extent to which chance influences development. Practical consequences, in the long-term, not only reduce the participation base and narrow the performance pathway, but also impact on the overall health of SA domestic and international game. Findings also reinforce the theoretical models, acknowledging sports development as an individual and non-linear process and confirm cricket as a late developing sport, stressing the importance of those development environments between mass participation and elite performance (school/club/university) to retain structure, competition and exhibit the greatest flexibility and coherency. Implications for practice and research are discussed.
\end{abstract}




\section{The effects of structural change: An investigation into the South African cricket}

\section{development pathway}

As prominence on the international sporting stage becomes ever more significant, so does the importance of talent identification and development programmes. These structural and organisational challenges are faced by most sports, whether it be from the increased demands of government funding agencies due to the success attached to Olympic medal tables or to appease the demands from the fans, directors and shareholders that accompany world and competition rankings (Grix and Brannagan 2016, Cruickshank and Collins 2012). As a consequence, domestic sporting structures need to be as effective as possible in consistently producing internationally competitive athletes (Bailey and Collins 2013, De Bosscher et al. 2008). Given the long-term nature of talent development (e.g. Martindale et al. 2005), it becomes ever more important to map the development trajectory of sportspeople from novice to elite level, as well as to understand how each element within the development pathway interacts to facilitate or hinder effective progression.

Numerous elements, both organisationally and structurally are required to work coherently if someone is to progress from a talented young athlete to successful adult (Martindale et al. 2007). For example, policy developments require integration across a number of factors, such as financial support, foundation of participation, adequate training facilities, talent development and identification systems, coach provision and support and international competition (De Bosscher et al. 2006, De Bosscher et al. 2008). In part, past research investigating effective organisational approaches to elite system development have stressed the importance of aligning sports policy decision-making and the implementation of resources through strategic sports programs (De Bosscher et al. 2006, Sotiriadou and Shilbury 2009). In 
addressing the methodological issues surrounding measuring the ${ }^{1}$ effectiveness of elite sports systems, De Bosscher et al. (2006) offer a conceptual framework for analysing Sports Policy Factors Leading to International Sporting Success (SPLISS, Figure 1). The SPLISS is a comprehensive model acknowledging key drivers that can be influenced by sports policies (De Bosscher et al. 2009). In accordance with the multidimensional approach to measure effectiveness of national sporting agencies (Chelladurai et al. 1987, Chelladurai 2001), the model is set across two-levels and is clustered into nine areas, or pillars, that are considered important across the stages of athletic development. An important aspect of the SPLISS is that in order to effectively produce consistent outputs, a coherent, integrated and long term approach is required (De Bosscher et al. 2006).

[Figure 1 near here]

As athletes progress from novice to elite, a number of them will drop out of the sport, leaving only a few to reach elite level. In this way the SPLISS forms a pyramid, as athletes progress through Pillars 3, 4 and 5 (De Bosscher et al. 2006). Conventionally, mass participation and elite development were to be viewed as reliant on one another (De Bosscher et al. 2013). This depiction of the pyramid metaphor is for those sports that require a large participation base (input) in order to form the stable underlying structure of a hierarchical staged progression to elite status. The mutual dependency proposition lies in the fact that young

\footnotetext{
1 The Sports Policy Factors Leading to International Sporting Success. De Bosscher, V., De Knop, P., Van Bottenburg, M., \& Shibli, S. 2006. A conceptual framework for analysing sports policy factors leading to international sporting success. European Sport Management Quarterly, 6 (2), 185-215 copyright (C) European Association for Sport Management, reprinted by permission of Taylor \& Francis Ltd, http://www.tandfonline.com on behalf of European Association for Sport Management
} 
aspiring athletes will be drawn along the development path in the hope of gaining recognition and elite status (De Bosscher et al. 2013). In terms of sports psychology literature, the pyramid metaphor or Standard Model for Talent Development (SMTD) (Bailey and Collins 2013) has received much criticism. In practice, much of the criticism levelled against the SMTD is due to the model focusing solely on progressing those adolescent athletes identified as talented (Bailey and Collins 2013). Identification, often too early, can lead to a number of individuals being removed from the system, even though they meet the identifiable standard later on (Bailey et al. 2011, Bailey and Collins 2013.)

Even though the SPLISS model is described as an inclusive model, as it outlines those factors impacting on elite performance, it has also been described as too generic and not sport specific (Sotiriadou et al. 2013) due to the critical success factors or key determinants of success being different across sports or certain types of sports (De Bosscher 2007, Larose and Haggerty 1996). Furthermore, it stands to reason that even though these factors may be evident, the way they are implemented or utilised, in driving success, is as important (Sotiriadou et al., 2013). With that in mind, very few answers are given to the questions 'what' or 'how' the elements surrounding a specific sport may be drivers of performance.

Separately, within the sport psychology related research, numerous elements have been identified in talent development environments as useful in facilitating progression (Henriksen and Roessler 2011, Martindale et al. 2007), including long term vision, clear developmental agendas with a de-emphasis on early performance success, with integration and coherence between significant personnel.

In terms of individual differences, there are a vast and varied number of constraints as to why an individual may or may not achieve elite sporting success. Constraints have been associated with individual differences in training and performance responses due to genetic diversity (Davids and Baker 2007) and/or how these individual differences transmit to the 
environmental learning context. Factors may also specifically relate to the learning and the quality of instruction received (Csikszentmihalyi et al. 1993, Davids and Baker 2007), together with the volume of extended and deliberate practice (Ericsson et al. 1993) or the resilience or commitment of the athlete (e.g., Fletcher and Sarkar 2012, Macnamara et al. 2010)

In relation to the pathway itself, there is a significant area of research outlining the importance of key stages and transitions occurring within the development environment that the individual needs to negotiate on the way to becoming an elite level athlete. For example, the rationale relating to personal, social and contextual variables behind the successful development of talent has led to the development of a number of progressive, staged multidimensional athlete development models (Bloom 1985, Côté 1999, Stambulova 1994, 2000, Wylleman and Lavallee 2004). A common aspect across each of the models is the importance of the athlete transitioning across certain stages in order to achieve success.

Staged process models provide useful insight into the attitudes, experiences and support processes attached to development, however more recent research has highlighted the importance of recognising the process of development as non-linear (Martindale et al. 2007). Furthermore, transitions and challenges for athletes are likely to occur simultaneously across different life domains, increasing the complexity. For example Wylleman and Lavallee's (2004) development lifespan model outlines a layered approach, indicating that as athletes make the transition between development and mastery they are also progressing from adolescence to (young) adulthood, and potentially transitioning from secondary to higher education. This model, together with other staged models (Bloom 1985, Côté 1999) and those embedded in organisational psychology (De Bosscher et al. 2006), while presenting useful insights, do not account for the complexities of development and the different pathway 
options available within specific contexts or cultures, such as the club or academy environments, that may lead to elite success.

For the context of this study, research has shown the development trajectory of a cricketer to be long (Weissensteiner et al. 2009) and over this time, the athlete, through agerelated programs, will face a number of limiting factors (Weissensteiner et al. 2009). For example, Muller and Abernethy (2006) identify cricket batting as a difficult and complex time-constrained interceptive skill. Through their study of 14 male expert cricket batsmen, coaches and administrators, Weissensteiner et al. (2009) highlighted the importance of biological, psychological and socio-developmental factors required for cricket batting expertise to emerge. Alongside, Ranson et al. (2009) established cricket bowling as a changeable highly complex motor skill which requires talent development programs to encourage late specialisation and also take into consideration the effects of rate-limiting constraints such as different learning, growth and maturation rates (Phillips et al. 2010). In their study of the development trajectory of eleven Australian international fast bowlers, Phillips et al. (2010) ascertained that certain aspects of the development environment were intrinsic to the elite performer's development, such as the importance of late specialisation, stressing at the same time the importance of a robust, unique and dynamic support network which comes in many forms found between family, school and club (Wolfenden and Holt 2005, Henriksen and Roessler 2011).

Theoretically, these different approaches highlight the immense challenge that sports organisations have in coordinating talent development processes, and stress the importance of investigating and identifying how the different variables, or elements, of a successful development pathway interact. This complex interaction may be exacerbated by structural change and sports policy decision-making, at the macro level, having a profound effect, not only changing the way the pathway elements interact and individuals progress, but also on the 
quality of the learning and development domain at the micro-level. There is very little research examining not only the impact of structural change on development progression, but also the complex interaction of developmental elements along the pathway.

Finally, the importance of cultural context is significant. In the past, South Africa's sporting structures have predominantly focused on provincialism and provincial competition. Within a cricketing context, the continued focus on provincial structures changed for the first time when the General Council of the United Cricket Board (now Cricket South Africa or CSA) voted in the September of 2003 to drastically cut the 11 professional teams that made up the domestic first class and limited overs competition to 6 franchises, with the agreed changes coming into affect from the $7^{\text {th }}$ April 2004 (Louw 2010). The decision to reduce the number of provincial teams was due to a number of reasons. The first was because of the considerable financial losses incurred as revenue and gate money were not sufficiently covering the costs of running the professional domestic competitions (Louw 2010). The second was to increase the performance of the national team and to close the perceived gap between provincial and international cricket (Louw 2010).

Over the course of South Africa's (SA) sporting history there has been a noteworthy connection between politics and sport. During the apartheid years and SA's isolation from international cricket, the domestic game was run by three different organisations, the SA Cricket Association (SACA), the SA Board of Cricket Control (SABOC) and the SA Cricket Board (SACB). SABOC was formed in 1947 to administer games amongst the Black, Coloured and Indian populations (Odendaal 1977 as cited in Nauright 2010). It was only in the December of 1990, prompted by the pending release of Nelson Mandela and the subsequent political power-sharing negotiations between the African National Congress and SA's ruling National Party, did the black governed SACB agree to merge with the white governed SACU to form 
the United Cricket Board of SA (UCBSA or UCB, now Cricket South Africa) and in so doing become the first sport in SA to reach full unity (Nauright 2010).

The sporting and socio-cultural history amongst population groups within SA is extremely complex and far beyond the scope of this paper. Consequently, in order to address the aim of this investigation and to successfully undertake a like-for-like structural comparison between SA cricket development pathways pre-2004 and post-2004 it was necessary to only include and refer to those development elements overseen and governed by the then UCB, post 1992. This was deemed necessary in order to remove differences in development opportunities offered to different racial groups during apartheid. Considering this, the development environments outlined within Cricket South Africa’s Long-Term Participation Development (LTPD) Programme, from Grassroots to Proteas (Ferreira 2011) provided the focus of this investigation. The LTPD programme outlines the cricket development 'pipeline' in SA as a pyramid structure, with players being introduced to the game at KFC Mini-cricket (formerly Bakers Mini-cricket) then progressing to youth and schools cricket. Youth (provincial) and schools cricket act as a feeder system to senior cricket, involving club, tertiary, academy and provincial level cricket. After senior cricket and just below the national team (Proteas) are the franchise and high performance programme levels.

Before continuing, there are a number of external factors that require acknowledgement due to their potential influence on the SA development pathway. The first of these factors is that of quota systems. The first of the SA national teams to return to international competition, post unification, was predominantly white. Unhappy with the speed at which transformation of the racial make-up of the national team was occurring, the ANC, in 1997, formulated a more aggressive approach to affirmative action, with quotas being introduced to accelerate the process. Since then racial quotas (or targets) have received much debate. Currently, quotas systems (or targets) exist across all teams and are still in place 19 years since being enforced. 
Importantly, within CSA's Integrated Annual Report (2016/17) the lack of adequate facilities and adequate support from local government to grow the game in disadvantaged areas is still viewed as a high strategic risk to the organisation. It may be argued, it is for these reasons transformation targets are still necessary in order to equalise opportunities for players of colour. Recently, in an attempt to make cricket truly accessible to all, CSA have set yet further aggressive transformation targets for its national team, outlining measures that require an average minimum number of black players representing the national team at any one time (ANA 2016 in press).

The second factor is what has become known as the Kolpak agreement. The Kolpak agreement came into affect on the $8^{\text {th }}$ May 2003 and allowed for the free movement of sports people across the European Union (EU), regardless of sports organisations restrictions. Maros Kolpak, a Slovakian Handball player, for whom the European Courts of Justice ruled in favour, was not from the EU but rather from a country with a trading relationship with the EU. This opened up similar opportunities for sportspeople in other countries with the same trading relationship, such as SA, Zimbabwe and parts of the West Indies to exploit (Desai and Vahed, 2015). At the time Desai and Vahed (2015) explained that around 50 SA cricketers had used the Kolpak clause, however since then a number of national players, Kyle Abbott, Rilee Rossouw, Hardus Viljoen and Stiaan Van Zyl have left the SA national system to take up Kolpak contracts in the English County Leagues. It could be argued the actions of promising players such as these leaving the system may have a short-term impact on the overall strength of the national team.

In an attempt to address the aim of this paper, neither of these factors will be focused upon in any detail. The choice to do so may be viewed as a limitation, however the effects of political transformation are unique to a SA sporting environment and including these factors in the investigation would diminish the possible generalisability of findings across other sporting 
environments. To add, the scale of the topic may detract from more comparable findings. Excluding these factors in no way lessens the importance of the topics and their associated effects, however future research may wish to exclusively investigate the impact of the Kolpak agreement and transformational change.

After 28 years of sporting isolation, following SA's re-entry to international competition in 1992, the country again competed at international level and immediately reasserted itself as one of the top cricketing nations in the world. With very little nonpoliticised literature on the subject, the question of what SA's talent development environment looked like in order to produce internationally competitive teams, after 28 years of isolation, remains relatively un-reviewed. In addition, the change from a provincial to a franchise structure at the domestic elite end of the development continuum offered a unique opportunity to investigate the impact of change on the elements of a successful sports development pathway and one of SA's oldest and most established sports.

Subsequently, the aim of this study is to gather a practical understanding of the development pathway of SA cricketers and to investigate if the changes made to the provincial structure in 2004 have impacted on the post-2004 development trajectory of a SA cricketer.

\section{Methodology}

\section{Pragmatic Research Design}

Identified as an approach that may benefit the exploration of performance sport environments (Cruickshank et al. 2014), the pragmatic approach offered the researcher the scope to be recognised as a co-constructor of knowledge. In this way pragmatism supports the construction of knowledge by identifying applied artefacts rather than generalised truths (Giacobbi et al. 2005, Savage et al. 2016, Cruickshank and Collins 2015) thus allowing the researcher to focus on providing practical and meaningful insights (Giacobbi et al. 2005, Morgan 2007) for the benefit of the environment under consideration. 
In establishing the practical concern between the researcher and the research subject it was important to recognise the contextual experience of the researcher. The researcher was born in SA and gathered significant and in-depth experience of the provincial age-related provincial development programme at domestic youth and national level, whilst at the same time gathering professional first class experience at three different provinces between the years 1990 and 2000. It was due to the researchers former background as a professional first class cricketer in SA that allowed access to the uniquely experienced coaches, players and administrators used within this study. Access to such uniquely experienced participants increased the opportunity of achieving community agreement and provided practical-level truths that were able to assist in providing meaningful and useful information for SA cricket (Giacobbi et al. 2005).

While a pragmatic philosophy is often associated with a mixed methods approach, by encapsulating both quantitative and qualitative methodologies (Creswell 2003, Cruickshank and Collins 2016), it was decided that, due to the importance of participant perceptions and the explorative nature of the study, a qualitative, semi-structured interview was the most appropriate approach to adopt in order to investigate the structure of the development pathway in SA cricket (Gould et al. 2007, Cruickshank and Collins 2016).

Even though the pragmatic approach accepts researcher bias and prejudice, by considering the researcher as a part of the research process (Giacobbi et al. 2005, Denzin and Lincoln 2008, Cruickshank and Collins 2016), it was important to structure the interview script in such a way for any reference to the 2004 structure change to emerge from the interview discussions (Cushion and Jones 2006, Nash et al. 2011). In order to facilitate this, the primary questions were to be as broad and open-ended as possible, where prompts and probes were used to explore each broad, primary question in more depth (Côté et al.1995).

\section{Participants}


In adopting a pragmatic approach (Giacobbi et al. 2005), it was essential to purposefully select (Coyne 1997) individuals who could, not only offer insight into the SA cricket development environment, but also provide an historical perspective, prior to the structural change in 2004. In addition, requirements were to select those individuals who could also offer a perspective from multiple viewpoints relating to the development pathway by engaging a uniquely experienced representative sample across all levels of SA cricket.

The sample consisted of 12 current and former players, coaches and administrators, all of which had gathered experience ranging from a minimum of eight years to a maximum of 46 years operating and playing in the SA cricketing environment. The minimum requirement of eight years related to participants being able to provide a pre-2004 perspective, calculated from when the data was collected. Except for coach 3 and player 3, all playing-experience calculations began at the start of a first-class cricket career. Due to the nature of this investigation and that SA woman's cricket was not as well established, with a governed and structured development environment in comparison to the men’s game pre-2004, all interviewees were male, with coaching and playing experiences embedded across both male youth and adult cricket.

At the time of interview, all participants had been involved in their current position for a minimum of two years. Inclusive of this, all identified participants (excluding coach 3 and player 3) had gathered between eight and 21 years of experience as SA domestic elite cricket players. The number of participants included in this study is consistent with the earlier studies conducted by Nash et al. (2011).

Participants included a former CSA board and current Chairman of a provincial board $(n=1)$, Chief Executive Officers ( $n=3)$, Franchise Head Coaches ( $n=2)$, Franchise Assistant Coach ( $n=1)$, Provincial Coaches ( $n=2)$, International and first class cricketers $(n=2)$ and club cricketer ( $n=1)$. A significant advantage to identifying these specific participants related to all 
having gathered multiple experiences over time, thus enabling them to provide a unique perspective. All selected coaches would hold a coach qualification of Level 3 and/or Level 4 and be either current employees of Cricket SA or their respective cricket boards, while all participants identified as administrative had gathered on-field experience of the SA development environment as former first class players. To add, the club player had been involved in club cricket for over 15 years, across a number of regions, and gathered experience of playing in numerous national club competitions.

\section{Procedure}

Before participants were identified, all procedures were pre-approved by Edinburgh Napier Universities’ ethical committee. Once identified, each participant was recruited by personal contact and informed consent obtained to take part in a one-to-one interview. In order to promote honest evaluation and maintain trustworthiness, assurances were provided that anonymity would be protected and none of the organisations or bodies involved in employing the participants would have access to the recorded information (Golden-Biddle and Locke 2007).

Even though the researcher had a close connection to the environment, there were a number of occasions that the initial approach to some participants, such as CEOs was halted by the gatekeeping process, as a number did not respond to an interview request. Importantly, the previous experience gathered from within the SA development environment allowed the researcher to establish, not only a level of credibility with the participants, but also a level of trustworthiness that proved very useful when exploring the more sensitive topics. It may be argued that without this level of experience and connection with the research subject this level of disclosure and access to credible and uniquely experienced participants would not have been achievable. 
All interviews were conducted by the first author and took place at various locations across South Africa. Individual interviews were either at the training ground or in individual private offices and averaged approximately 45 minutes. Each interview was recorded on a Dictaphone for later transcription. Due to the retrospective nature of the enquiry each participant was asked to complete a basic structural schematic of what they thought the structure of SA cricket to be, with distinct changes demarcated by chronological events. The structural schematic aided recall and allowed the formation of a framework to assist the interviewing process of all participants (Cruikshank and Collins 2012). As the interview process progressed each participant was asked to comment on the structures.

\section{Data Analysis}

Inductive thematic analysis, outlined by Braun and Clark (2006), was adopted due to the flexible and uncomplicated approach it offers to analyse a multifaceted topic. The first part of the inductive process was to become familiar with the data by way of multiple readings of the transcribed data. The second stage was to group the data by generating codes across the whole data set. From this coding procedure, themes were formed and all relevant coded data was grouped and applied to each theme. Once applied, the themes were reviewed in relation to the coded extracts and a thematic map was produced. Even though it is possible for two individuals to apply the same level of subjectivity to a piece of text (Loffe and Yardley 2004), the reliability of the coding and theming procedure was checked by an experienced, critical friend in an attempt to remain as objective as possible (Vaismoradi et al. 2013). The product of the thematic mapping process is outlined in Figure 2.

The first column of Figure 2 outlines the general themes that emerged after the initial coding and theming process. The second column of the table represents the five main themes that emerged once the coded data was reviewed and themes defined. Each theme was then renamed in order to present a clear definition that sufficiently represented each theme. The 
themes were then arranged in the most appropriate way in order to clearly present the findings of the phenomenon under investigation. This process was especially helpful when observing links between pre and post 2004 structural changes (Morse and Field 1995).

[Figure 2 near here]

\section{Results and Discussion}

The five main emergent themes are intentionally positioned to represent the ways in which structure change, at a franchise level, has impacted in a variety of ways on the structure and function of the feeder development environments lower down the development system. This is demonstrated by the first theme representing the most immediate effect of the structural change at the domestic elite level and concluding with the final theme representing the perceived changes at the school development level. This top down approach was also adopted with the intention of demonstrating the interrelated nature of a talent development pathway from novice participation through to elite performance.

\section{Loss of opportunities at highest level}

This first theme contextualises the differences between Australia and SA, highlighting the difficulties associated with the adoption of an external system.

Prior to the launch of the new franchise system on the 7th April 2004, the domestic structure of SA cricket consisted of eleven provinces and approximately 160 professional cricketers. This reduction allowed each franchise to offer 18 professional contracts.

'The challenge at the moment is there are 11 provinces and six franchises. This means 160 professional players has now reduced to 100 . This means a huge number of opportunities are gone.’ (Administrator 4) 
The process of modelling the new franchise structure to the Australian structure is perceived to create a new franchise system that is less inclusive due to the reduction in the opportunities for individuals to reach the top domestic level.

'They tried to model it on the Australian system but Australia, by the nature of the beast have only got six States, so each State has got a team, so you know, we have got a hell of a diverse culture here, we have got to... our goal should be to afford the opportunity for as many people as possible, to be afforded the opportunity to play for SA...' (Administrator 4)

The need for sports policy strategy to be decisive and responsive to stay ahead of the competition leads countries to adopt and apply previously successful policies and development structures, in the hope that the associated success becomes part of the adopted nation (Collins and Bailey 2012). Policy adoptions strategies such as these may not take into account the sociocultural differences and development pathway sensitivities that are rooted in the fabric of the host environment.

\section{Selection stagnation: The reduction in flexible multiple pathways}

The second theme highlights a number issues, namely the reduction in the number of opportunities at the top franchise level, particularly to late developers, leading to selection stagnation further down the development pathway. This selection stagnation has been exacerbated by a perceived decline in the competitiveness and strength of feeder environments leading to a lack of selection flexibility across development elements.

The structure and competitiveness of provincial cricket prior to change was perceived to have had the effect of reducing the number of provinces and impacting on the overall number of cricketers SA produces. In the past, having 11 provinces meant there were more better performing cricketers for SA to choose from and more opportunities for development along the pathway. 
'Without opportunity you are never going to get anywhere. Wherever you are. You are always going to have three top provinces or franchises, which is now, with six teams we have got three top ones, that is it. We had more top ones when there was $11 \ldots . . . .$, like I said, the base just keeps dwindling and you get less and less cricket but if you get opportunity there is more space to play, you are producing more cricketers ....' (Coach 5)

The general perception of the pre-franchise system was the significant number of pathway options available to young aspiring cricketers after school.

In the early 1990’s (Figure 3), there were two available options to a young cricketer after completing school, both which were related to socio-political factors at the time. The options depended on whether they chose to join the SA Army (national conscription was compulsory until approximately 1994) or delay conscription and go to university first. Due to the availability of only two development environments after school typically meant that each of those environments enjoyed an annual influx of the very best of SA sporting potential.

[Figure 3 near here]

At the time, the previous importance of the army and the flexibility of the pathway to allow late developers, without having played age-group representative cricket, to progress was not only confirmed, but also current changes to this progression had become apparent.

‘The only oke (guy) that come into my head was (name of player), he didn't play at school, he hardly played first team at school, the feeder system was still good enough then for him to go to the army and break through, play provincial cricket and go on to 
become a SAn all-rounder. But those guys aren’t going to appear anymore, I wouldn’t say. They are not going to come through the system.’ (Player 3)

Noted purely as an example to ensure participant confidentiality, the Cape Cobras franchise team are fed by two affiliates (provinces): the Western Province Cricket Association and the Boland Cricket Board (Figure 4).

[Figure 4 near here]

In theory, this system should provide a competitive performance-based development environment for players to progress into franchise cricket, leading to a more competitive professional domestic environment (Douglas and Martindale 2008). In contrast, the opposite seems to have occurred, with selection to franchise level not seemingly based on performance measures due to the perception that any performance at amateur level was produced in an inferior environment and therefore deemed incomparable.

'You have got guys that have done poorly. They are good players, they really are good players, but they underperform and then you have got the guys below them in like an amateur environment performing massively, like awesomely and they don't really get the opportunity to play because invariably the system is weak below. So the guy at the top will just keep underperforming for a certain amount of time.......but if the foundation is weak in the sense that if those guys (selectors) don't really believe in the performances that are happening, whether they are good or bad, then it actually means nothing.' (Coach 5)

The negative perception that exists around the domestic provincial system is not only confirmed, but also the lack of progression due to limited opportunities at elite level and franchise’s being considered as ‘closed shops’ is highlighted (Martindale et al. 2005). 
'There are players playing in the so-called amateur leagues, provincial leagues, that have no hope, at this stage, of going through to franchises. I believe that there is not enough scope for them at a higher level to play cricket........Franchises are limited. Franchises are closed shops. Even though they are not supposed to be. The only way they are going to get opportunities are to broaden the bases at higher level.' (Administrator 4)

The combined reduction in the number of competitive flexible pathways, together with negative perceptions of feeder environments, has led to barriers limiting progression across formal threshold measures (Bailey and Collins 2013) such as club/provincial and franchise.

\section{Reduction in pathway opportunities leads to loss of older participants and early identification and selection}

The following theme brings to the fore the importance of those development environments after school (such as the club) to offer meaningful learning, developing and competitive opportunities in order to keep them in the game, particularly for those cricketers not selected for either provincial or franchise level opportunities (Martindale et al. 2007).

The overall reduction in the number of elite cricket teams is perceived to have contributed to a reduction in the opportunities for cricketers above the age of 24 . The implications of which means individuals around this age may now leave the game due to the lack of opportunities.

'There are not enough cricket teams in SA, too many cricketers are not playing the game and leaving a vacuum from the ages of 24 onwards as there are no opportunities.

The current franchise system was to mirror the Australian system, but it’s not right for SA because SA has a far larger population to consider.' (Administrator 4) 
There is a perception that even though some individuals have been selected after the age of 27 and without having been part of the provincial pathway structures, more often than not 25-27 years of age appears to be an age-related threshold to play domestic elite level cricket.

'Look it is a difficult one...I have seen 27, 28 years olds come back and do really well without having played in any of your structures below, without being in an academy, (but) without wanting to rule a line straight through club cricket, I just think it is ever harder for your 25, 26, 27 year old to get back in. I probably say if you haven’t made it by that age you are only ever going to play recreational cricket. That is probably what the system lends itself to.' (Coach 3)

After school, a strong club structure should offer a credible development environment for those individuals who do not get selected for a franchise contract. However, due to a weak club structure, the system offers fewer development opportunities for those individuals who may be late developers (Phillips et al. 2010, Ranson et al. 2009).

Club level doesn't exist anymore. Club level at the moment is an absolute mess throughout the country. You get schools level, they do quite a lot at under 19 level...They are identified at under 19 level, they put them through academies but from then on there is actually nothing for them to go...if doesn't go from under 19 to franchise. He has got nothing. And the guy that doesn't get identified, you know you get late developers, you get guys that for whatever reason, they don't get taken up to the under 19 system, those guys are lost to cricket. There is no club system.' (Administrator 2)

Evidence suggests that the pathway is far more complex and interrelated than the pyramid system may suggest. A number of researchers (e.g., Vaeyens et al. 2008) have highlighted potential problems of early specialisation and that of dropout or burn out (Wall 
and Côté 2007) in young adolescents, with very little research applied to adults, especially within the context of progression in relation to the pyramid metaphor.

This flawed process may be problematic for adult performers too, due to the threshold measures of club/tertiary/provincial/academy environments often leading towards individuals being selected or de-selected for progression (Bailey and Collins 2013). However it is the inflexibility of the pyramid process that creates issues for those de-selected. Progression across each threshold not only means large numbers of individuals are removed from the next level, but it can become difficult for those de-selected to return. Due to this lack of progression it would not be unrealistic for adults to exit a sport due to not only the attractiveness of alternative options (Scanlan et al. 1993), but also due to a lack of selfdetermination and satisfaction (Ryan and Deci 2000).

Earlier evidence relating to the reduction of a competitive standard of development environments, together with the lack of opportunities for older or late developing cricketers both reaffirm and encourage early identification, selection and development in an environment that may be controlled by coaching staff. The difficulty with this approach is that it may narrow selection further down the development pathway Below, confirms a strategy of not only identifying talent early, but rather of developing and keeping them within their development system (Martindale et al. 2005, 2007).

'So the culture here is to identify talent early and run with them. Not that guys don't come in from the side, but it hasn't been the culture of (name of province) to buy players in. It is more of a culture of developing what we have got and giving guys the opportunity to develop. It is very sad for us when someone leaves our system, we try and keep them here as much as we can.’ (Coach 2)

When considering the context specific nature of sports development a number of researchers have highlighted the skills of batting and bowling as difficult and complex skills 
to master (Muller and Abernethy 2006, Ranson et al. 2009) which requires talent development programs to encourage late specialisation and also take into consideration the effects of rate-limiting constraints such as different learning, growth and maturation rates (Phillips et al. 2010). For example, in their study of the development trajectory of 11 Australian international fast bowlers, Phillips et al. (2010) found that a significant proportion of experts did not decide to specialise in the skill until their late teens. This confirms Côté et al.'s (2007) assertions that the investment years begin after 16 years plus, and stresses the importance of late specialisation and a robust, unique and dynamic support network which comes in many forms found between family, school and cricket club (Weissensteiner, et al. 2009, Phillips et al. 2010).

It was also perceived that the number of players coming from the tertiary education sector has reduced due to fewer individuals going to university. This factor, coupled with the diminishing strength of club cricket, creates a challenge for provincial bodies to provide the best environment to develop players from the age of 18 when they leave school to the age of 23, the current average of the professional cricketer.

'Your tertiary sector still delivers a lot of international players, but it is far less as people don't go and study anymore which is we have found. And then from amateur, our average age for professional cricket is 23 so our biggest challenge that we are going to have is the age they finish school to 23. That age we need to look after.' (Administrator 1)

When relating these findings to earlier evidence and to the late developing nature of the sport, it seems that the development pathway is not providing adequate learning and development environments for players of a certain age (18-23 years) who are not involved in provincial and franchise system structures. The perceived lack of an alternative environment offering competitive development opportunities may ultimately lead to losing players at a 
crucial stage in the pathway, just when they should be developing sporting maturity (mental, physical, technical and tactical preparation) (Phillips et al. 2010, Wylleman and Reints 2010). Development dislocation: Coherency and quality of sub-elite development environments

The following theme highlights a number of issues related to the development environments at the sub-elite level. The development and competitive credibility of these environments are brought into question, specifically concerning the coherency across environments, the quality of coaching offered and promotion of short-term performance outcomes at the expense of longer-term development (Mallet and Hanrahan 2004, Martindale et al. 2005, 2007).

By their very nature, academies were implemented for adolescent cricketers in order to provide a stepping-stone to full representative provincial honours. The difficulty for academies and club cricket to co-exist is highlighted, due to the academy taking the place of club cricket for players below a certain age. It seems those players in the system development environments, such as the academy, have made redundant those development environments outwith the system (such as club cricket), especially for those individuals over a certain age group.

'I don’t think clubs and academies can coexist. I just don’t think enough kids are involved at clubs anymore. Once they are finished (with school), matriculated or whatever, they don’t play with a club, simply because they think 'well if I haven’t made it in an academy now there is no real route mapped out for me, I am just going to fall by the wayside so I might as well find myself a job’ or whatever other distractions there are.' (Coach 3)

The importance of not only developing the game at grassroots level, but also providing a coherent structure and good quality coaching along the participant pathway is confirmed. In SA not all children will have the benefit of good quality coaching or facilities 
at school, emphasising the role of the club as a very necessary step in the development pathway for the SA player (Wolfenden and Holt, 2005, Henriksen and Roessler 2011). ‘The maintenance isn’t there. The sustainability isn’t there. Bakers has been unbelievable and mini cricket is still an unbelievably...it is mushrooming now. Now you have got all those players, now they want to start playing hardball cricket, where does our infrastructure catch them? We are getting a lot of feedback from schools saying ‘you are not running the game effectively enough, efficiently enough’, kids are getting frustrated. You turn up for fixtures, there is no opposition, the pitches are crap, people aren’t doing enough work on the ground, you are going to lose those kids.' (Coach 4)

An environment whereby children are de-selected at U/13 level if they do not reach certain performance indicators is described. The effect of which establishes a lack of importance placed on a long-term approach to skill development at the younger age group by focusing on short-term success as the sole outcome (Martindale et al. 2005).

'At the moment, at a senior level we have all these academies and we don't have real academies at a junior level trying to enhance skill levels. What we do is, we have academies and we will just pick the elite kids, at every level you keep discarding them, where is the net for the leftover cricketers who maybe in later life develop and become more mentally aware and their skill development is late in life, but we have already throw them away at U/13 level, because they could make (name) and we stop developing them.’ (Coach 5)

This is an indicative feature of the pyramid development model that focuses on unreliable short-term performance measures of predicting talent (Vaeyens et al. 2008, Bailey and Collins 2013). The detriments of this approach have been raised by a number of 
researchers such Fraser-Thomas and Côté (2009) who highlight the effect of this policy as reducing the pool of potential elite athletes from an early age.

Importantly, it is perceived that affiliate level cricket is not fostering a competitive environment to develop cricketers that may compete for selection at franchise level. The lack of providing a competitive development environment at this crucial transition point highlights the importance of quality competition being an integral part of a development pathway in order to produce elite performers (Douglas and Martindale 2008).

'There is a massive gap between $80 \%$ of the players at provincial level and the players at franchise level. If you look at a franchise team and how a franchise team should operate and how they warm up and be professional, then you look at an amateur side and there are club sides that do it better. So what you call first class cricket and you give a semi-professional tag is not that at all. There are a few guys who do it right, but out of the 14 teams, there are a lot of guys who don't do it right.' (Coach 2)

The importance of the lower levels to remain competitive in order to produce players who have the skill level to place selection pressure on the individuals who have franchise contracts is established. As previously mentioned, maintaining the competitive strength and processes of lower development environments is crucial to the sustainability of development pathways (Douglas and Martindale 2008) and confirms that the academy environment may not be producing the competitively prepared cricketers it was originally established to do.

It has been recognised that the gap between the school and the club is widening and academies are not helping to bridge this gap, thus potentially forcing the flawed and problematic policy of identifying talent earlier along the development pathway (Wall and Côté 2007). 
'SA relies heavily on the school system and there is a huge gap between the schools and the franchise. The academy has come in, but it hasn't done much.'

(Administrator 3)

A change within the school development environment is also confirmed. In the past, formal cricket masters would coach cricket, leading to a better quality of instruction and practice. The quality of instruction that, in the past, was provided by formal cricket masters is perceived to no longer be taking place. In addition, teacher workloads have increased, thus leaving them less time to dedicate to sports.

'...your formal coaching, your better coaching, might have been, back in the day, at your schools in SA. I don’t think it is the case anymore, because you don't have your proper cricket masters anymore. The education system is such that teachers are just flooded with work and there is no time for your extra murals if you want.' (Coach 3) There appears to be a number of issues that have arisen for a particular age and stage of the SA cricketer. These findings not only confirm the interrelated nature of the development environment but also raise practical issues that relate to the perceived lack of competitive strength within each sub-elite development environment that operate between the school and the franchise.

\section{The changing school environment}

This final theme emphasises the perceived importance of the school structure as a development environment to SA cricket. Significantly, it also highlights that the school development environment is changing due to issues such as changes to teaching patterns and an emphasis on shortened games. This theme also confirms provincial school and U/19 level cricket as an important selection threshold to progress to the professional game.

A number of interviewees described SAn cricketers as hardworking, hard practising and mentally tough cricketers, with the school playing a major part in developing these 
attributes (Bull et al. 2005). In developing these attributes, SA has relied heavily on its formal school structures and the schooling system for developing its sportspeople.

'Our system has always been through schools and through clubs, it is dependent on the schools, there is no question.' (Administrator 3)

As highlighted earlier, cricket contains a number of skills that require time and a consistent approach to developing the underlying technique in order to become successful (Weissensteiner et al. 2009, Phillips et al. 2010). The change in the school environment, as an important development environment, has been become apparent because essential fundamental skills are not being embedded due to a lack of skilled practitioners who understand the importance of these fundamental skills to the long-term success in the game (Ford et al. 2009, Weissensteiner et al. 2009).

'Routines are very important to practice and building the right attitude with the emphasis on hard work and self-development. Schools are important in this process but it does mean going to the right school, which have the right coaching methods and practice and will give the right exposure. An issue with the schools process is the lack of male teachers to constantly ground the fundamentals of the game, at the moment the easier option of the shortened game is chosen at the detriment of the fundamentals of technique.' (Coach 1)

The importance that certain affiliate provincial administrations place on the application of correct coaching practice is highlighted, so much so that they are willing to control and pay for its delivery.

'In SA, with regards to the school system the big issue here is the involvement of teachers, you don't get the dedicated teacher who actually coaches any more, they are few and far between. They actually rely on the unions (provincial governing bodies), so we send out guys to the schools and we pay for that.' (Administrator 4) 
The above not only establishes the importance of the school system, it also highlights the importance of the correct coaching personnel at the school level and reinforces the coach as a key driver in the construction of the learning environment (Mallet and Hanrahan 2004; Phillips et al. 2010).

While the importance of players being identified at U/19 level in order for professional progression is emphasised, it also highlights this area of transition where a significant proportion of individuals may be lost if not selected.

'Let’s assume a guy went to (name of private school), he doesn't make the Nuffield

Side or the Coca Cola (SA Schools team) now, his cricket is finished, over. (Name of former SA national player), for instance, he never played Nuffield Cricket, that wouldn’t happen today. He can still go to Nuffield and if he is not picked out of Nuffield he can still be lost and that is the area I am saying a lot of people are lost at.' (Administrator 2)

The above statement confirms the importance of the development environments after school, to assist with progression and bridge the gap between school and elite performance, not only from a performance perspective but also for continued participation (Ford et al. 2009).

\section{Conclusion}

The aim of this study was to gain an understanding of the development pathway of SA cricketers and to investigate if the changes made to the provincial structure in 2004 have impacted on the post-2004 development trajectory of a SA cricketer.

Findings emerged that structural change has played a partial role in creating stressors further down the development continuum, especially at the sub-elite level between the school and franchise environments. A number of interrelated and practical issues become apparent as a consequence of structural change; a) The reduction in opportunities at the top level of 
domestic cricket, b) The loss of competitive standard of club and affiliate (provincial) level cricket has lead to a reduction in viable pathway options, c) Provincial and franchise level coaches reduce the identification of talent from club, tertiary and provincial cricket environments due to the perceived lack of competitiveness, d) The importance of representative age-related academies is stressed as a fundamental development environment,

e) The importance of age related identification has removed talented young adolescent cricketers from the club structure, f) Clubs play less of a role in the development pathway due to a weaker and less competitive club environment not enabling a culture of talent development and positive role modelling, g) Adolescent cricketers may begin specialising earlier in an attempt to be part of each affiliate internally controlled development structure and h) Adolescent cricketers who have developed later may find themselves in a learning and development environment that may lack progression, due to factors such as quality of competition, and are more likely to exit the game altogether, thus driving down the average age of the SA cricketer. Inclusively, structural change has also seemingly increased the possibility of chance (Gagne 2010) within the development pathway, due to the vagaries of maturation and development (Vaeyens et al. 2008), coupled with a coach’s perception and preconceived selection criteria impacting on whether individuals will progress across threshold measures.

\section{Theoretical Implications}

This study reinforces previous theoretical models that acknowledge sports development as individual and non-linear in process (Abbott et al. 2005), by highlighting the complex, challenging and contextual nature of sports development environments that are not accounted for by the staged multidimensional athlete development models (Bloom 1985, Côté 1999, Stambulova 1994, 2000, Wylleman and Lavallee 2004). In addition, these challenges and 
complexities make it difficult within certain sports to relate development to that of tapering, unidirectional and staged development of the pyramid metaphor (Bailey and Collins 2013).

This, together with the confirmation of cricket as a late developing sport (Phillips et al. 2010) highlights the importance for the development environments after school, and below domestic elite, to, not only retain structure and competition, but also exhibit selection flexibility and coherency between a wider number of development elements, rather than be constrained to a single, narrowly defined pathway with limited options. These findings reinforce those of Martindale et al. (2005) who suggested a social environment through the provision of practice and play, which in this context may be found in the school and club environments, together with coherent avenues for transition and support, can be a major influence on the progression in a cricketing development pathway. Findings also reinforce the importance of the coach and the quality of instruction provided within these important transitional development environments, especially due to the late developing nature of the game (Mallet and Hanrahan, 2004, Phillips, et al. 2010). To add, by exhibiting flexibility and coherency between a broader group of development environments, rather than focusing development on a narrowly defined pathway, may allow for increased flexibility and a more individualised approach that is aligned to the sport specific developmental requirements explained by Weissensteiner et al. (2009) and Phillips et al. (2010).

As outlined earlier, De Bosscher et al. (2006) conceptual framework offers significant insight in developing an understanding of the sport policy factors that lead to international sporting success. However, the context specific nature of how the nine pillars within the SPLISS framework actually apply in practice is limited. This study has built upon this framework to describe how for example, Pillars 3 (Foundation \& Participation); Pillar 4 (Talent identification and Development Systems) and Pillar 5 (Athletic and Post Career Support) are applied in practice, and how each requires an integrated approach in order to 
facilitate success. It also highlights the need to carefully consider the impact of changes to one pillar on other pillars or structures within a sporting system. The need for a coherent and integrated approach across all identified development environments has clear implications for the South African cricket system.

\section{Practical Implications}

Not all the outcomes highlighted in this study can be associated to the structural change of 2004. The outcomes may also, in part, relate to socio-political changes that took place in the mid-1990's affecting the development environments after school, such as the significantly reduced impact of the army on the development pathway and the associated effect this may have had on tertiary education cricket. In addition, there are other significant macro-level effects that may influence the nature and effectiveness of the SA cricket development pathway, such as the aforementioned transformation quotas or target arrangements or the effect of the Kolpak agreement (Desai and Vahed 2015), all impacting in some way on the opportunities of players reaching elite level competition.

In considering the overall health of the game it is important for SA cricket to focus attention on the development elements within the aforementioned areas of transition, together with the current role the provincial/affiliate academy plays in player development. For example, to not only consider the role of the provincial academy in the competitive development of young cricketers, but how the academy provides a flexible, coherent and competitive bridge between the school, club, provincial and franchise environments. Attention should also focus on the maintaining the overall competitive strength of the school, club, tertiary and provincial environments.

Maintaining the competitive strength of these developmental elements may influence the older and more experienced players to remain in the game for longer, while at the same time impacting positively on the learning environments for young players. For example, in order to 
increase the overall strength of the club environment would be to focus on the administrative, coaching and leadership functioning of the club and to ensure the club environment plays an increasingly significant role in providing both social and sporting development aspects for the overall improvement of cricket development opportunities in SA. In the past, it may be argued the club environment received players rather than developed players by relying on both the nature of the development pathway and competitive strength of the environment. Due to, not only the change of focus away from the club environment, but also the noted lack of adequate facilities and local government support to grow the game, clubs cannot remain a passive development environment, but need to be more proactive in their leadership and administration to regain lost ground to again be an integral part of the development process, particularly during and after school.

It is also important to not only consider each development element in isolation, but rather how each may provide a competitive advantage for the other. For example, it is important to not only consider the connection upwards between the school, club, tertiary environments and provincial environment, but to also consider what the provincial environment can offer downwards, such as positive player role modelling and expectation management for developing players to observe the behaviours required to progress.

Bearing in mind the significant focus on mass participation, by CSA also focusing attention on the competitive strength and coherency between the school, club, tertiary and provincial environments may impact positively on increasing the selection flexibility across development elements and reduce possible developmental stagnation and dislocation between these environments, thus reducing the possible effects of player drop-out. These considerations may also lead to a positive effect on increasing the opportunities for players from all social and racial backgrounds, thus more broadly and better reflecting the socio-political changes that are 
taking place in SA and, in the longer term, reduce the need for racial quotas or targets to be in place.

\section{Future Considerations}

Current theory and empirical investigations within talent development and high performance environment research often focus on narrow environmental contexts, such as small groups and teams (e.g. an athletics club; high performance squad). As such, this study adds to our understanding of, and the need to consider, how different elements of the sporting system (both structural and socio-political) operate and integrate to facilitate or debilitate the development of elite athletes throughout different stages of the pathway. In so doing, this study offers a practical, real-world example of the context and individual nature of a development pathway with structural change highlighting sensitive areas of the development pathway endemic to a SA context. The sensitive areas highlighted may, in the long-term, not only lead to a reduction in the participation base at these crucial stages of transition but may also contribute to further narrowing of the performance pathway. These two factors may impact on the overall health of the SA domestic game and international performances in the future. Further work is required to understand the learning and development domains across a range of different sports in order to, not only be better informed when adopting cross-cultural policy and strategies (Collins and Bailey 2012) but to also understand where in a pathway sensitive areas of transition exist in order for player development to be supported more effectively.

\section{References}

Abbott, A., Button, C., Pepping, G., and Collins, D. 2005. Unnatural selection: Talent identification and development in sport. Nonlinear Dynamics, Psychology, and Life Sciences, 9 (1), 61-88.

ANA. 2016 CSA set aggressive transformation target 
Available at:https://www.iol.co.za/sport/cricket/proteas/csa-set-aggressivetransformation-target 2064275

Bailey, R.P., Leigh, J., Pearce, G., \& Reeves, M. 2011. National impact evaluation of the gifted and talented physical education and sport programme. Loughborough: Youth Sport Trust.

Bailey, R., and Collins, D. 2013. The Standard Model of Talent Development and Its Discontents. Kinesiology Review, 2 (4), 248-259.

Bloom, B.S. 1985. Developing talent in young people. New York: Ballantine.

Braun, V., and Clarke, V. 2006. Using thematic analysis in psychology. Qualitative Research in Psychology, 3(May 2015), 77-101. Available from: http://doi.org/10.1191/1478088706qp063oa

Bull, S. J., Shambrook, C. J., James, W., and Brooks, J. E. 2005. Towards an understanding of mental Toughness in elite English cricketers. Journal of Applied Sport Psychology, 17 (3), 209-227. Available from:

http://doi.org/10.1080/10413200591010085

Collins, D., and Bailey, R. 2012. "Scienciness” and the allure of second-hand strategy in talent identification and development. International Journal of Sport Policy and Politics.

Chelladurai, P., Szyszlo, M., \& Haggerty, T. R. 1987. System-based dimensions of effectiveness: The case of national sport organisations. Canadian Journal of Sport Sciences, 12, 111-119.

Côté, J., Salmela, J. H., \& Russell, S. 1995. The Knowledge of High-Performance Gymnastic Coaches : Methodological Framework. The Sport Psychologist, 9, 65-75.

Côté, J. 1999. The influence of the family in the development of talent in sport. The Sport Psychologist, 13, 395-417. 
Côté, J., Horton, S., MacDonald, D., and Wilkes, S. 2007. The Benefits of Sampling Sports During Childhood. Physical \& Health Education Journal, 1-7.

Côté, J., Turnnidge, J., and Evans, M. B. 2014. The dynamic process of development through sport. Kinesiologia Slovenica, 20 (3), 14-26.

Coyne, I. T. 1997. Sampling in qualitative research. Purposeful and theoretical sampling; merging or clear boundaries? Journal of Advanced Nursing, 26 (3), 623-630. Available from:

http://doi.org/http://dx.doi.org/10.1046/j.1365-2648.1997.t01-25-00999.x

Cricket South Africa (CSA) 2016-2017 Annual Integrated Report available from: http://cricket.co.za/cat/19/Governance/3396/CSA-Annual-Reports/

Creswell, J. W. 2003. Research design Qualitative quantitative and mixed methods approaches. Research Design Qualitative Quantitative and Mixed Methods Approaches, 3-26.

http://doi.org/10.3109/08941939.2012.723954

Cruickshank, A., \& Collins, D. 2012. Change Management: The Case of the Elite Sport Performance Team. Journal of Change Management, 12 (2), 1469-7017. Available from:

http://doi.org/10.1080/14697017.2011.632379

Cruickshank, A., \& Collins, D. 2015. Illuminating and Applying “The Dark Side”: Insights From Elite Team Leaders, Journal of Applied Sport Psychology, 27 (3), 249-267, DOI: $10.1080 / 10413200.2014 .982771$

Cushion, C., \& Jones, R. L. 2006. Power, Discourse, and Symbolic Violence in Professional Youth Soccer: The Case of Albion Football Club. Sociology of Sport Journal, 23(142), 142-161.

Csikszentmihalyi, M., Whalen, S., Wong, M., and Rathunde, K. 1993. Talented teenagers: 
The roots of success and failure. New York: Cambridge.

Davids, K., and Baker, J. 2007. Genes, environment and sport performance: Why the naturenurture dualism is no longer relevant. Sports Medicine. Available from: http://doi.org/10.2165/00007256-200737110-00004

De Bosscher, V., De Knop, P., Van Bottenburg, M., \& Shibli, S. 2006. A conceptual framework for analysing sports policy factors leading to international sporting success. European Sport Management Quarterly, 6 (2), 185-215. Available from: http://doi.org/10.1080/16184740600955087

De Bosscher, V. 2007. Sports policy factors leading to international sporting success. Belgium: VUBPRESS, Brussels

De Bosscher, V., Bingham, J., Shibli, S., van Bottenburg, M., and De Knop, P. 2008. A Global sporting arms race. An international comparative study on sports policy factors Leading to international sporting success. Aachen, DE: Meyer \& Meyer.

De Bosscher, V., De Knop, P., van Bottenburg, M., Shibli, S., \& Bingham, J. 2009. Explaining international sporting success: An international comparison of elite sport systems and policies in six countries. Sport Management Review, 12 (3), 113-136. http://doi.org/10.1016/j.smr.2009.01.001

De Bosscher , V., Sotiriadou, P., \& van Bottenburg, M. 2013. Scrutinizing the sport pyramid metaphor: an examination of the relationship between elite success and mass participation in Flanders, International Journal of Sport Policy and Politics, 5 (3), 319-339

Douglas, C., and Martindale, R. 2008. Player development review for PRL. PB Performance, UK.

Desai, A., and Vahed, G. 2015. Beyond the nation? Colour and class in South African cricket ictepin Desai, A. The race to transform: sport in post-apartheid South Africa.

Ericsson, K. A., Krampe, R. T., and Tesch-Römer, C. 1993. The role of deliberate practice in 
the acquisition of expert performance. Psychological Review, 100 (3), 363-406.

Ferreirra, A. 2011. Long-term participation development programme, from Grassroots to Protea. Available from: http://www.sascoc.co.za/wp-content/uploads/2013/04/Cricket-LTPD-Nov-2011.pdf

Fletcher, D., and Sarkar, M. 2012. A grounded theory of psychological resilience in Olympic champions. Psychology of Sport and Exercise, 13 (5), 669-678. Available from: http://doi.org/10.1016/j.psychsport.2012.04.007

Ford, P. R., Ward, P., Hodges, N. J., \& Williams, A. M. 2009. The role of deliberate practice and play in career progression in sport: the early engagement hypothesis. High Ability Studies, 20 (1), 67-75. Available from:

doi: $10.1080 / 13598130902860721$

Fraser-Thomas, J., and Côté, J. 2009. Understanding Adolescents ' Positive and Negative Developmental Experiences in Sport. The Sport Psychologist, 23, 3-23.

Gagné, F. 2010. Motivation within the DMGT 2.0 framework. High Ability Studies.

Giacobbi, P. R., Poczwardowski, A., and Hager, P. F. 2005. A Pragmatic Research Philosophy for Applied Sport Psychology. Journal of the Sport Psychologist, 19, 1831.

Golden-Biddle, K., and Locke, K. 2007. Composing qualitative research: Sage.

Gould, D., Greenleaf, C., Chung, Y., \& Guinan, D. 2002. A survey of U.S. Atlanta and Nagano Olympians: variables perceived to influence performance. Research Quarterly for Exercise and Sport, 73 (2), 175-186. Available from:

http://doi.org/10.1080/02701367.2002.10609006 
Grix, J., and Brannagan, P. M. 2016. Of Mechanisms and Myths: Conceptualising States’ “Soft Power” Strategies through Sports Mega-Events, Diplomacy \& Statecraft, 27 (2), 251-272, Available from:http://dx.doi.org/10.1080/09592296.2016.1169791

Henriksen, K., and Roessler, K. K. 2011. Riding the wave of an expert : A successful talent development environment in kayaking. The Sport Psychologist, 25, 341-362.

Larose, K., \& Haggerty, T. R. 1996. Factors associated with national Olympic success: an exploratory study. Unpublished masters thesis. Universiteit Brunswick, Canada.

Loffe H., and Yardley L. 2004. Content and thematic analysis. In: D.F. Marks and L. Yardley L. eds. Research Methods for Clinical and Health Psychology. 1st ed. London: Sage Publications.

Louw, A. 2010. Sports law in South Africa. Kluwer Law International.

Macnamara, Á., Button, A., and Collins, D. 2010. The role of psychological characteristics in facilitating the pathway to elite performance part 1 : Identifying mental skills and behaviors. The Sport Psychologist, 24, 52-73. Available from:

http://doi.org/10.1080/03634520802237383

Mallett, C. J., \& Hanrahan, S. J. 2004. Elite athletes: why does the ‘fire’ burn so brightly?. Psychology of Sport and Exercise, 5 (2), 183-200.

Martindale, R., Collins, D., and Daubney, J. 2005. Talent development: a guide for practice and research within sport. Quest, 57 (4), 353-375. Available from: http://doi.org/10.1080/00336297.2005.10491862

Martindale, R. J. J., Collins, D., \& Abraham, A. 2007. Effective talent development: the elite coach perspective in UK sport. Journal of Applied Sport Psychology, 19 (2), 187-206. http://doi.org/10.1080/10413200701188944 
Morgan, D. L. 2007. Paradigms lost and pragmatism regained methodological implications of combining qualitative and quantitative methods. Journal of mixed methods research, 1 (1), 48-76.

Morse, J. M., and Field, P. A. 1995. Qualitative research methods for health professionals. $2^{\text {nd }}$ ed. Thousand Oaks, CA: Sage.

Müller S, and Abernethy B. 2006. Skill learning from an expertise perspective: issues and implications for practice and coaching in cricket. In: J. Dosil, eds. The sport psychologist's handbook: a guide for sport-specific performance enhancement. London: John Wiley \& Sons.

Nash, C. S., Sproule, J., and Horton, P. 2011. Excellence in Coaching. Research Quarterly for Exercise and Sport, 82 (2), 229-238. Available from: http://doi.org/10.1080/02701367.2011.10599750

Phillips, E., Davids, K., Renshaw, I., and Portus, M. 2010. The development of fast bowling experts in Australian cricket. Talent Development and Excellence, 2 (2), 137-148.

Ranson, C., King, M., Burnett, A., Worthington, P., and Shine, K. 2009. The effect of coaching intervention on elite fast bowling technique over a two year period. Sports Biomechanics / International Society of Biomechanics in Sports, 8 (4), 261-74. Available from: http://doi.org/10.1080/14763140903469908

Ryan, R. M., and Deci, E. L. 2000. Intrinsic and extrinsic motivations: Classic definitions and new directions. Contemporary educational psychology, 25 (1), 54-67.

Savage, J., Collins, D., \& Cruickshank, A. 2016. Exploring Traumas in the Development of Talent: What Are They, What Do They Do, and What Do They Require? Journal of Applied Sport Psychology, 1-17. http://dx.doi.org/10.1080/10413200.2016.1194910

Scanlan, T. K., Carpenter, P. J., Schmidt, G. W., Simons, J. P., and Keeler, B. 1993. An introduction to the sport commitment model. Journal of Sport \& Exercise Psychology, 
15 (1), 1-15. Available from: http://doi.org/10.5539/ijps.v3nlp90

Sotiriadou, K., \& Shilbury, D. 2009. Australian Elite Athlete Development: An

Organisational Perspective. Sport Management Review, 12 (3), 137-148. http://doi.org/10.1016/j.smr.2009.01.002

Sotiriadou, P., Gowthorp, L., \& De Bosscher, V. 2013. Elite sport culture and policy interrelationships: the case of Sprint Canoe in Australia. Leisure Studies, 4367(May 2015), 598-617. http://doi.org/10.1080/02614367.2013.833973

Stambulova, N. 1994. Developmental sports career investigations in Russia: A postperestroika analysis. The Sport Psychologist, 8, 221-237.

Stambulova, N. (2000). Athlete’s crises: A developmental perspective. International Journal of Sport Psychology, 31, 584-601.

Vaeyens, R., Lenoir, M., Williams, A. M., and Philippaerts, R. M. 2008. Talent identification and development programmes in sport: Current models and future directions. Sports Medicine.

Vaismoradi, M., Turunen, H., and Bondas, T. 2013. Content analysis and thematic analysis: Implications for conducting a qualitative descriptive study. Nursing and Health Sciences. Available from: http://doi.org/10.1111/nhs.12048

Wall, M., and Côté, J. 2007. Developmental activities that lead to dropout and investment in sport. Physical Education \& Sport Pedagogy.

Weissensteiner, J., Abernethy, B., and Farrow, D. 2009. Towards the Development of a Conceptual Model of Expertise in Cricket Batting: A Grounded Theory Approach. Journal of Applied Sport Psychology, 21(3), 276-292. Available from: http://doi.org/10.1080/10413200903018675 
Wolfenden, L. E., and Holt, N. L. 2005. Talent Development in Elite Junior Tennis:

Perceptions of Players, Parents, and Coaches. Journal of Applied Sport Psychology, 17 (March 2015), 108-126. Available from:

http://doi.org/10.1080/10413200590932416

Wylleman, P., and Lavallee, D. 2004. A developmental perspective on transitions faced by athletes. Developmental sport and exercise psychology: A lifespan perspective, 507527.

Wylleman, P. and Reints, A. 2010. A lifespan perspective on the career of talented and elite athletes: Perspectives on high-intensity sports. Scandinavian Journal of Medicine \& Science in Sports, 20: 88-94. Available from:

doi:10.1111/j.1600-0838.2010.01194.X 


\section{Figures}

Figure 1: The Sports Policy Factors Leading to International Sporting Success (De Bosscher et al. 2006)

Figure 2: Theme review process

Figure 3: An example of the South African cricketing pathway pre-2004 franchise restructuring

Figure 4: An example of the post-2004 South African franchise structure 


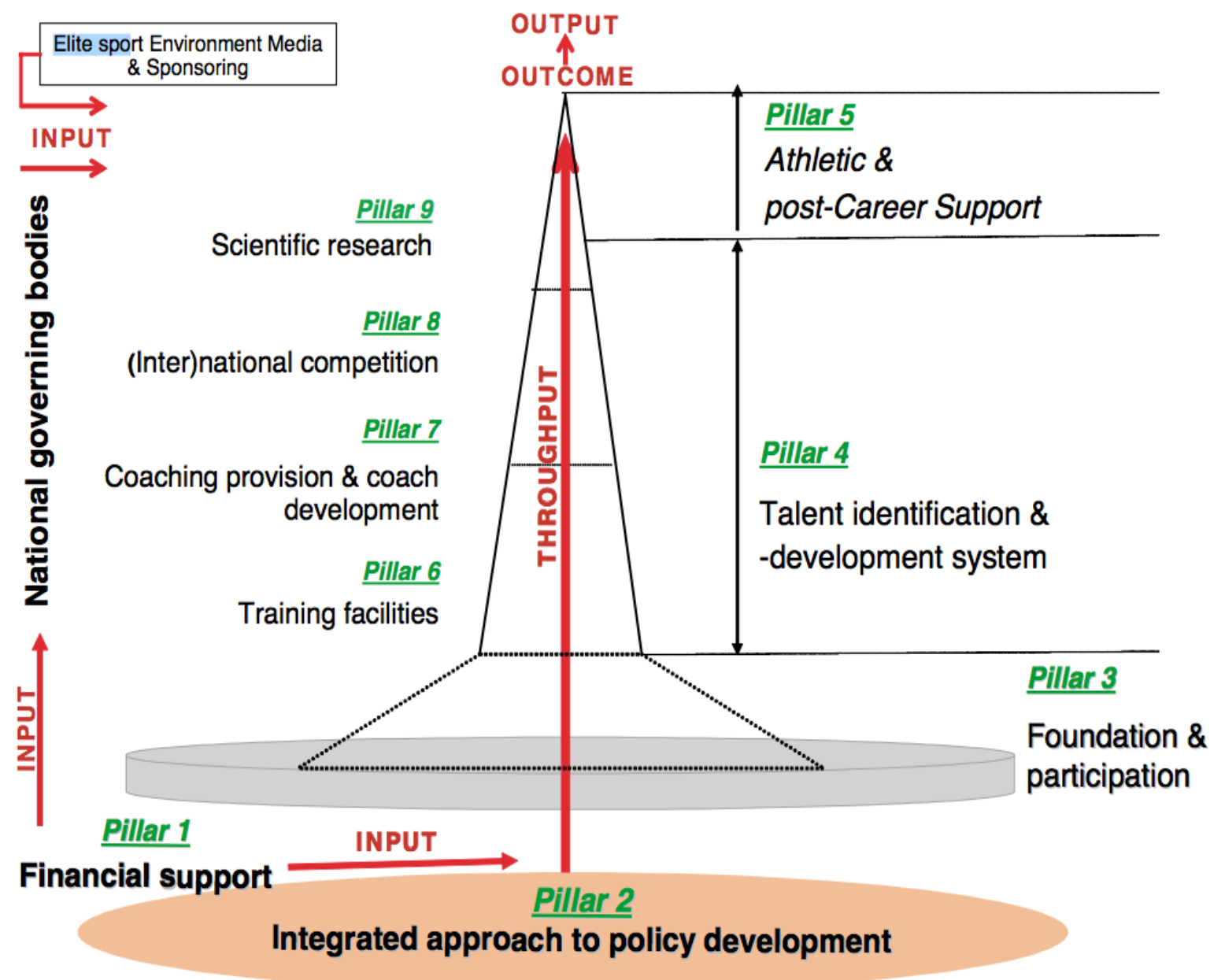




\begin{tabular}{|l|l|}
\hline General theme structure & Final theme structure \\
\hline Environmental Differences & $\begin{array}{l}\text { Loss of opportunities at the highest } \\
\text { level }\end{array}$ \\
\hline Reduced opportunities and challenges & $\begin{array}{l}\text { Selection stagnation: Reduction in } \\
\text { flexible multiple pathways }\end{array}$ \\
\hline $\begin{array}{l}\text { Decreasing opportunities due to } \\
\text { change }\end{array}$ & $\begin{array}{l}\text { Reduction in pathway opportunities } \\
\text { leads to a loss of older participants and } \\
\text { early identification and selection }\end{array}$ \\
\hline $\begin{array}{l}\text { Problematic relationship of the club } \\
\text { and academy }\end{array}$ & $\begin{array}{l}\text { Development dislocation: Coherency } \\
\text { and quality of sub-elite development } \\
\text { environments }\end{array}$ \\
\hline $\begin{array}{l}\text { Vital role of school in developing } \\
\text { culture and play }\end{array}$ & \begin{tabular}{l} 
The changing school environment \\
\hline
\end{tabular}
\end{tabular}


SA National Team (Proteas)<smiles>C1=CC=C1</smiles>

South African 'A' team

SA Academy<smiles>C1CCC1</smiles>

Army Tertiary SAU/19 CD Development

Westem Province ( $1^{\text {st }}$ class)<smiles>[C+]1C=CC=C1</smiles>

Westem Province 'B' ( ${ }^{\text {st }}$ Class)<smiles>C1CC1</smiles>

Westem Cape Club cricket<smiles>C1CCCC1</smiles>

Westem Cape schools cricket

$$
\uparrow
$$
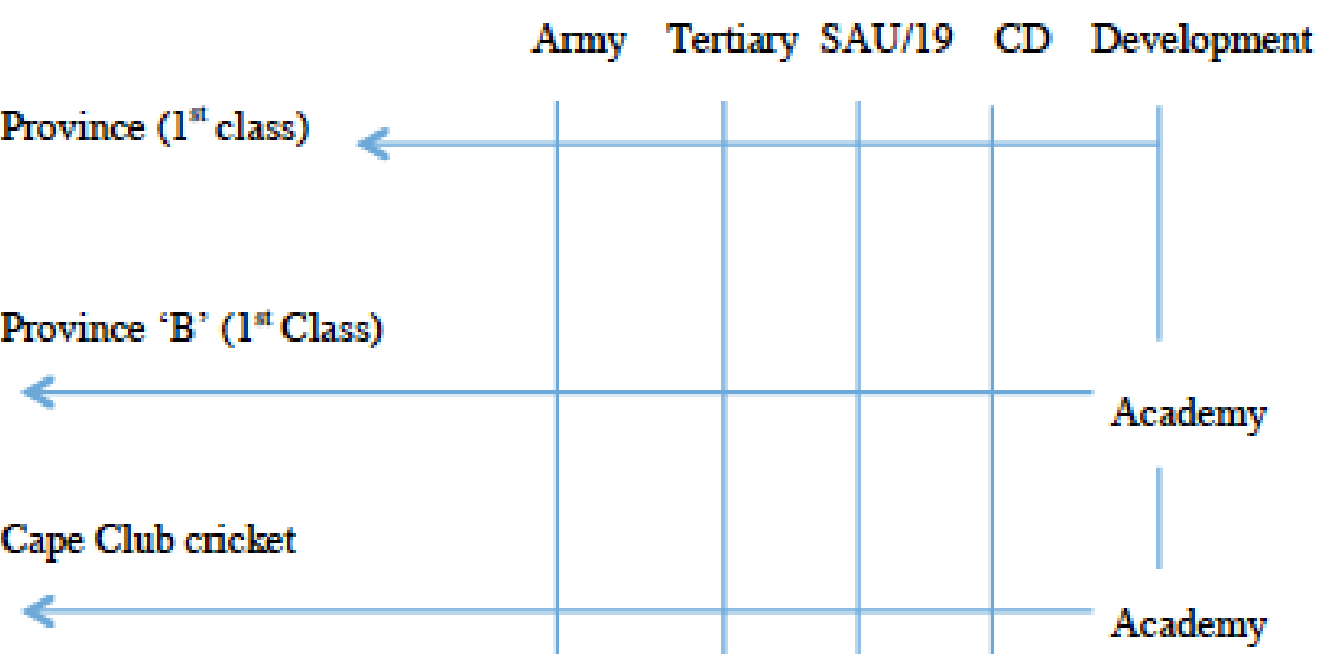

Academy

Introduction to cricket (Bakers Mini-cricket)

Age related representative cricket 


\section{Proteas}

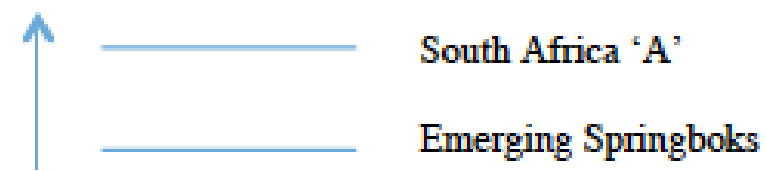

High Performance Centre

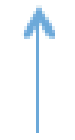

Cape Cobras

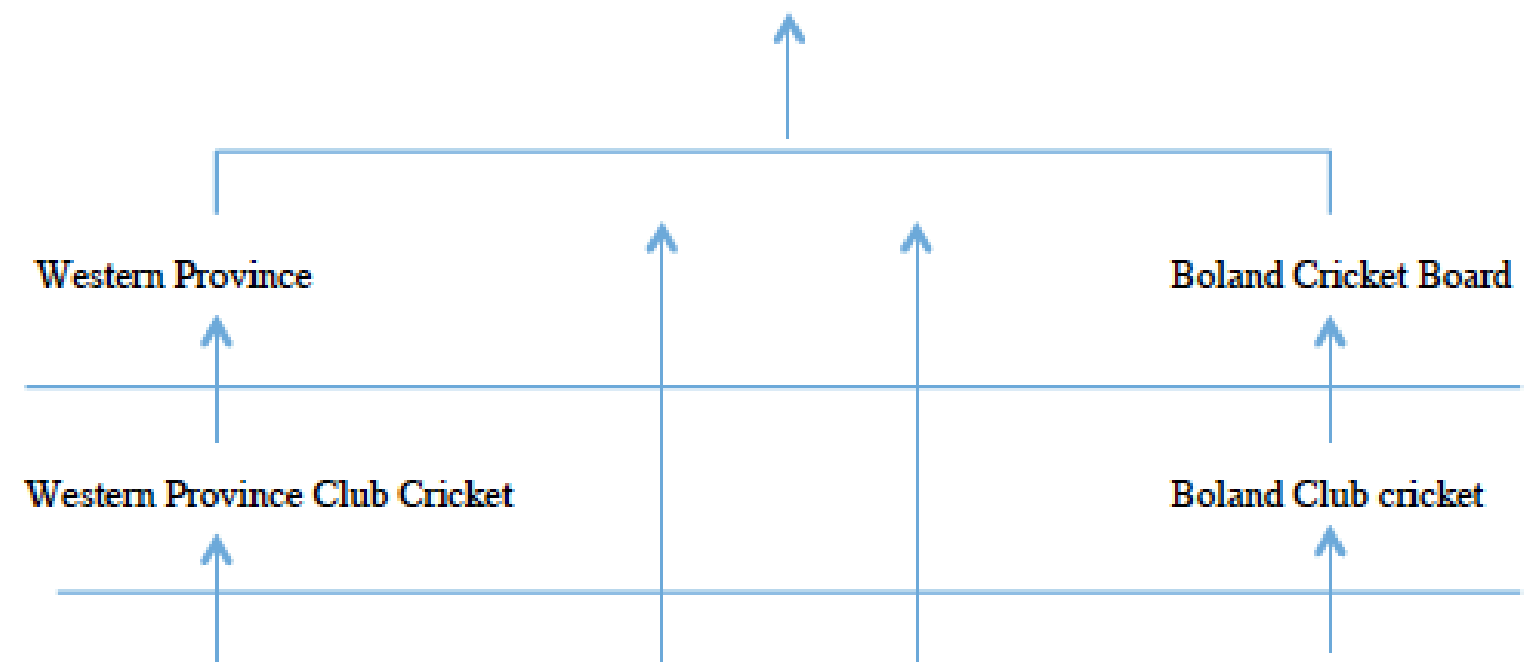

Western Cape Schools cricket

SA/U19

Boland Schools cricket

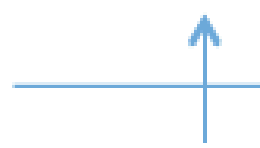

Introduction to cricket

Introduction to cricket 